\title{
The motor theory of social cognition: a critique
}

\author{
Pierre Jacob ${ }^{\mathbf{1}}$ and Marc Jeannerod ${ }^{\mathbf{2}}$ \\ ${ }^{1}$ Institut Jean Nicod, UMR 8129, CNRS/EHESS/ENS, 1 bis, avenue de Lowendal, 75007 Paris, France \\ ${ }^{2}$ Institut des sciences cognitives, 67, boulevard Pinel, 69675 Bron, France
}

\begin{abstract}
Recent advances in the cognitive neuroscience of action have considerably enlarged our understanding of human motor cognition. In particular, the activity of the mirror system, first discovered in the brain of nonhuman primates, provides an observer with the understanding of a perceived action by means of the motor simulation of the agent's observed movements. This discovery has raised the prospects of a motor theory of social cognition. In humans, social cognition includes the ability to mindread, and many motor theorists of social cognition try to bridge the gap between motor cognition and mindreading by endorsing a simulation account of mindreading. Here, we question the motor theory of social cognition and give reasons for our skepticism.
\end{abstract}

\section{Introduction}

Motor theories of human cognition are ubiquitous. Our topic is the motor theory of social cognition. The remarkable discovery of so-called 'mirror neurons' (MNs) in the ventral pre-motor cortex (area F5) of macaque monkeys [1-3] and the discovery of the mirror system in humans [4-7] have raised the prospects of a 'motor theory of social cognition', whose goal is to derive human social cognition from human motor cognition [8-12]. MNs are sensorimotor neurons that fire both when a monkey executes certain kinds of actions and when the monkey perceives the same actions being performed by another [1-3]. By automatically matching the agent's observed movements onto her own motor repertoire without executing them, the firing of MNs in the observer's brain simulates the agent's observed movements and thereby contributes to the understanding of the perceived action [1-3]. Thus, MNs supply motor, not purely perceptual, representations of actions. Because they are located in the pre-motor cortex, MNs should not fire in an observer's brain unless the represented action was executable, that is, consistent with the rules of the motor system [13-14]. We therefore think that one important function of MNs might be to enhance learning technical skills by allowing motor imitation $[2,15]$ (but see Box 1). However, we are skeptical about the view that MNs constitute the fundamental neural basis of human social cognition. In this article, we explain why.

\footnotetext{
Corresponding author: Jacob, P. (jacob@ehess.fr).
}

Available online 10 December 2004

\section{Human social cognition and mindreading}

In a weak sense, human social cognition encompasses all cognitive processes relevant to the perception and understanding of conspecifics [16]. So it includes, but it is not restricted to, the cognitive processes involved in the understanding of perceived actions performed by conspecifics. It is widely recognized that what is distinctive of human social cognition is the human mindreading ability to understand, not just the observable behavior of one's conspecifics, but also one's own mind (which we shall ignore here) and especially the minds of others [17-20]. Thanks to their mindreading ability, healthy human adults readily explain and predict human actions by representing and attributing to human agents a whole battery of internal unobservable mental states such as goals, intentions, emotions, perceptions, desires, beliefs, many of which are far removed from any observable behavior [21]. It is also intuitively clear that there is a gap between full-blown human mindreading and the psychological understanding of perceived actions afforded by MNs. Thus, the challenge faced by motor theorists of social cognition is to bridge this gap.

Faced with this challenge, the strategy favored by motor theorists of social cognition is to tinker with the concept of motor simulation, as suggested by simulation theorists of mindreading [8,10-12,22-23]. We disapprove this strategy because it relaxes the fundamental link between simulation and the requirements of the motor system, which we take very seriously. The firing of MNs is a social cognitive process only in a very weak sense. When MNs fire in the brain of a monkey during action execution, the discharge is not a social cognitive process at all. When MNs fire in the brain of a monkey watching another grasp a fruit, the discharge is a weakly social process: the two monkeys are not involved in any kind of non-verbal intentional communication. The agent intends to grasp a fruit, not to impart some information to his conspecific. Nor does the observer's understanding of the action require him to understand the agent's communicative intention (because the agent has none).

One way to question the motor theory of social cognition would be to challenge it to account for the human capacity to read one's own mind or to ascribe false beliefs to others something that healthy human adults do all the time without effort. But this is not what we shall do. Instead, we shall grant that simulating an agent's movements might be sufficient for understanding his motor intention, 


\section{Box 1. Mental simulation: a hybrid concept}

Mental simulation, of which motor simulation is an instance, is a hybrid concept: it involves at least two separable ingredients. One idea is that a cognitive mechanism can be used 'off-line'. For example, it has been suggested [45] that in visual imagery, the human visual system is used off-line: instead of taking retinal inputs, it receives inputs from memory. Instead of producing a visual percept, it produces a mental visual image. Thus, visual imagery consists in simulating visual perception or, as Gallese and Goldman [12] put it, 'in pretending to see' (p. 497).

The other idea is that mental simulation is the cognitive basis of imitation. A natural assumption is that the firing of MNs is the neural basis of motor imitation. MNs have been discovered in the brain of macaque monkeys. Do they imitate? Until recently, the evidence seemed negative [46]. But there is intriguing new positive evidence [47]. Interestingly, motor theorists of social cognition have taken two different, if not irreconcilable, positions on imitation. On the one hand, Gallese and Goldman [12] have strongly denied that a function of MNs is 'to promote learning by imitation' (p. 495-6). On the other hand, on behalf of the simulation theory (ST) of mindreading, they have

but we shall argue that it is not sufficient for understanding the agent's prior intention, his social intention and his communicative intention. Then, we shall argue that motor simulation may not even be necessary for understanding all perceived actions. Finally, we shall argue that a significant part of human social cognition consists of a 'perceptual social' system whose neural basis has perceptual but no motor properties [15,24].

\section{Motor simulation, motor intentions and prior intentions}

Evidence from brain imaging in healthy adults and autistic individuals suggests that reasoning about beliefs and representing goals and intentions are subserved by different brain areas [19,20]. Evidence from developmental psychology suggests that the former is a later and more costly accomplishment than the latter [17,18,25]. An action is a goal-directed sequence of bodily movements initiated and monitored by what we shall call a 'motor intention'. Understanding a perceived action requires at least representing the agent's motor intention. Although human adults readily explain actions by representing agents' (true or false) beliefs, it is possible, by relying on one's own current perception of the world, to represent the goal of a perceived action or the agent's motor intention without representing an agent's (true) beliefs. By simulating the agent's perceived movements, the observer can represent the agent's motor intention.

Indeed, before they can reason about beliefs, young children can represent goals and intentions [19,20]. After having been habituated to seeing a reach-and-grasp hand movement, five- to eight month-old infants look longer when the target of the prehension movement changes than when the path of the hand movement changes [26]. However, when grasping by a human hand is replaced by the motion of an artefact - for example, a metal claw - the pattern of preference elicited by seeing the movement of the human hand disappears [26]. This is compatible with the hypothesis that infants represent the goal of the action and the agent's motor intention by matching the observed hand movement onto their own motor repertoire - that is, by motor simulation. stressed the importance of imitation in tasks of third-person mindreading: 'ST depicts mindreading as incorporating an attempt to replicate, mimic, or impersonate the mental life of the target agent' (p. 497).

The main problem with imitation is that it is a folk psychological concept whose boundaries are presently too ill-defined for scientific purposes. Newborn babies, who reproduce facial movements of lip and tongue protrusion, are said to imitate [48]. And so are 18-monthold toddlers, who have been shown to be able to produce a correct version of an action of which they have observed an aborted version [49]. Does imitation reduce to copying? Or does imitation allow creative interpretation? Unless this ambiguity is resolved, it is hard to evaluate Meltzoff and Decety's claim that 'motor imitation' is 'the missing link' between $\mathrm{MNs}$ and 'theory of mind' [50]. If imitation requires copying, then, unlike observable behavior, beliefs cannot be imitated for they cannot be copied. If imitation is not restricted to copying and if creative interpretation is allowed as part of imitation, then perhaps even beliefs could be imitated. But one cannot have it both ways.

Philosophers, however, have long emphasized the distinction between basic actions and non-basic actions: for example, the non-basic action of turning on the light can be performed by the basic action of pressing a switch. They also make the correlative distinction between motor intentions (or 'intentions in action') and 'prior' intentions whose goals are more remote [27,28]. A motor intention is an intention to execute a basic action. Given one's prior intention to execute the non-basic action of turning on the light, one forms the motor intention to perform the basic action of, for example, pressing the switch with one's right index finger. Perceiving the basic action of pressing the switch with the right index finger automatically causes the observer to entertain the very motor representation that guides the agent's execution of the action. By executing the basic action, the agent also performs the non-basic action of turning on the light. The agent's basic action is controlled by his motor intention. His non-basic action is controlled by his prior intention. We surmise that by simulating the agent's perceived movement of pressing the switch with his right index finger, an observer will understand the agent's motor intention to execute the basic action, not his prior intention to execute the nonbasic action.

\section{Motor simulation and understanding social intentions}

Not all human actions are directed towards inanimate targets. Some are directed towards conspecifics. In addition to the distinction between motor intentions and prior intentions, an agent's non-social intentions must be distinguished from his social intentions, that is, his intentions to act on conspecifics, who, unlike inanimate targets of action, can act back. Thus, a social intention is an intention to affect a conspecific's behavior. Because humans often act out of their mental representations, a social intention can also be an intention to modify a conspecific's mental representations. The question is: could an observer represent an agent's social intention by simulating the agent's observed movements? As the following thought-experiment will show, it is unlikely that what enables an observer to represent an agent's social 
intention is the observer's ability to match an agent's perceived movements onto his or her own motor repertoire.

Consider Dr Jekyll and Mr Hyde. The former is a renowned surgeon who performs appendectomies on his anesthestized patients. The latter is a dangerous sadist who performs exactly the same hand movements on his nonanesthestized victims. As it turns out, Mr Hyde is Dr Jekyll. Suppose that Dr Watson witnesses both Dr Jekyll's and Mr Hyde's actions. Upon perceiving Dr Jekyll, alias Mr Hyde, execute the same motor sequence twice, whereby he grasps his scalpel and applies it to the same bodily part of two different persons, presumably the very same MNs produce the same discharge in Dr Watson's brain. Dr Jekyll's motor intention is the same as Mr Hyde's. However, Dr Jekyll's social intention clearly differs from Mr Hyde's: whereas Dr Jekyll intends to improve his patient's medical condition, Mr Hyde intends to derive pleasure from his victim's agony. By matching them onto his own motor repertoire, an observer simulates the agent's movements. Simulating the agent's movements might allow an observer to represent the agent's motor intention. We surmise that it will not allow him to represent the agent's social intention.

\section{Motor simulation and understanding communicative intentions}

MNs were first discovered in the context of motor and perceptual tasks that had a very weak social content, if any. As recognized by philosophers, psychologists and linguists studying pragmatics, especially complex among a human agent's social intentions are his (reflexive or selfreferential) communicative intentions. A communicative intention is an intention to impart information by virtue of its own recognition by the addressee [29,30]. Jill might have the social intention to cause Bill to believe that his wife is unfaithful to him without Bill's recognizing Jill's social intention. If so, then Jill's social intention is not a communicative intention. But Jill cannot have the communicative intention to cause Bill to acquire the same belief without Bill's recognizing Jill's communicative intention.

Now, consider Jill's non-verbal communicative intention whereby she intends to convey to John her desire to leave the party by ostensively pointing her index finger onto her wrist-watch in front of John. John thereby acquires the belief that Jill wants to leave the party by recognizing her communicative intention. Jill might, however, execute the very same ostensive bodily movement if she wants John to believe instead that her watch is inaccurate. Simulating Jill's movement of her right index finger towards her left wrist will allow John to represent Jill's motor intention. But it will not allow him to distinguish between Jill's two communicative intentions.

\section{Why motor simulation might not be necessary for understanding all perceived actions}

Simulating an agent's observed movements is not sufficient for representing either an agent's prior intention or his social intention. Is it necessary? Evidence from developmental psychology suggests that it is not: upon perceiving the relative motions of geometrical stimuli, 6-month-old infants automatically ascribe goals to them [31,32]. The question is: why do they ascribe goals to moving geometrical stimuli, and not to a metal claw moving towards a standing inanimate target [26]?

It has long been known that perceiving the relative motions of geometrical stimuli with no human or animal aspect (e.g. circles and triangles) can prompt normal adults to ascribe emotions and social intentions to the moving stimuli, which they describe using intentional verbs such 'chase', 'corner', 'attack', 'caress' or 'comfort' $[33,34]$. There is also evidence that 3-4-year-old toddlers respond like adults to the perception of Heider and Simmel type of stimuli [35]. Recently, when showed a triangle and a square whose motions were automatically seen respectively as 'helping' and as 'hindering' a circle move up a slope, 12-month-old infants exhibited a clear preference for the former over the latter [36].

Seeing the biological movement of a human hand reach and grasp a target prompts a human observer to represent the agent's motor intention by automatically matching the perceived movement onto her own motor repertoire [26]. Given the asymmetry between a moving human hand and its inanimate target, perceiving the action elicits the attribution of a motor intention, not of a social intention, to the agent. By contrast, geometrical stimuli form a homogeneous class of entities. Seeing geometrical stimuli move in relation to one another causes in humans a 'perceptual social illusion', that is, an illusion of social interactions guided by social intentions [33-36]. But given that the motion of geometrical stimuli is non-biological, it follows that the process whereby social intentions are represented and ascribed cannot be by matching the observed motions onto one's own motor repertoire, that is, by simulation in the narrow sense. Clearly, the process whereby geometrical stimuli are ascribed social intentions cannot be motor simulation.

Many social interactions are actions at a distance that involve an agent's head- and eye-movements towards or away from, but no direct bodily contact with, a conspecific. On the one hand, by the age of 7 months, human infants expect human interactions, unlike causal relations between inanimate objects, not to involve bodily contact [37]. On the other hand, much evidence from single cell recordings in the brain of macaque monkeys and from brain imaging in human adults suggests the existence of a purely perceptual system of 'social perception' [15,24] that can be tricked by perceptual illusions (the hallmark of perceptual systems). It involves the cooperation between at least three brain areas: the Superior Temporal Sulcus (STS), the amygdala and the orbito-frontal cortex $[15,19,24,34,38-41]$. Unlike neurons in F5 and in the inferior parietal lobule, which fire in response to the perception of object-oriented actions, many neurons in STS respond to the perception of others' actions directed towards conspecifics: they lack motor properties $[2,42]$ and they do not respond to the perception of one's own movements $[43,44]$.

There is a good reason why the perceptual response to a perceived action directed towards a conspecific would lack motor properties. The inanimate target of an 
object-oriented action does not act. As a result, the only movements which an observer can automatically match onto his own motor repertoire are the agent's. If, however, the target of a perceived action is a conspecific, then he or she will react. But then, the observer will simply be unable to automatically and simultaneously match onto his own motor repertoire the perceived movements of both agents. Only if he intentionally neglects one of the agent's observed movements will the observer be able to simulate the other's movements. This might be a case of motor simulation, but it is an intentional, not an automatic, process.

\section{Conclusion}

The mirror system is the mechanism whereby an observer understands a perceived action by simulating, without executing, the agent's observed movements. The motor properties of the mirror system are well designed for representing an agent's motor intention involved in an object-oriented action, not for representing an agent's social intention, let alone his communicative intention. The mirror system does not seem well designed for promoting fast responses to the perception of social actions directed towards conspecifics. For example, in response to the perception of a threat, it might be adaptive to flee, not to simulate the threatening agent's observed movements. Evidence from single cell recordings in the monkey STS shows that observing many actions towards conspecifics prompts purely perceptual responses without motor properties. Important for future research are questions relevant to the assessment of the scope of the primate system for pure 'social perception': for example, would a male monkey respond to the perception of a female's behavioral response to his own courting behavior by matching her observed movements? We predict that it would not.

\section{References}

1 Rizzolatti, G. et al. (1996) Premotor cortex and the recognition of motor actions. Brain Res. Cogn. Brain Res. 3, 131-141

2 Rizzolatti, G. et al. (2000) Cortical mechanisms subserving object grasping and action recognition: a new view of the cortical motor functions. In The New Cognitive Neuroscience (Gazzaniga, M. ed.), pp. 539-552, MIT Press

3 Rizzolatti, G. et al. (2004) A unifying view of the basis of social cognition. Trends Cogn. Sci. 8, 396-403

4 Rizzolatti, G. et al. (1996) Localization of grasp representations in humans by PET: 1. Observation versus execution. Exp. Brain Res. 111, 246-252

5 Grafton, S.T. et al. (1996) Localization of grasp representations in humans by PET: 2. Observation compared with imagination. Exp. Brain Res. 112, 103-111

6 Decety, J. et al. (1997) Brain activity during observation of action. Influence of action content and subject's strategy. Brain 120, 1763-1777

7 Fadiga, L. et al. (1995) Motor facilitation during action observation: a magnetic stimulation study. J. Neurophysiol. 73, 2608-2611

8 Gallese, V. (2003) The manifold nature of interpersonal relations: the quest for a common mechanism. In The Neuroscience of Social Interaction (Frith, C. and Wolpert, D. eds), pp. 159-182, Oxford University Press

9 Wolpert, D. et al. (2003) A unifying computational framework for motor control and social interaction. In The Neuroscience of Social Interaction (Frith, C. and Wolpert, D. eds), pp. 305-322, Oxford University Press
10 Blakemore, S-J. and Decety, J. (2001) From the perception of action to the understanding of intention. Nat. Neurosci. 2, 561-567

11 Metzinger, T. and Gallese, V. (2003) The emergence of a shared ontology: building blocks for a theory. Conscious. Cogn. 12, 549-571

12 Gallese, V. and Goldman, A. (1998) Mirror neurons and the simulation theory of mindreading. Trends Cogn. Sci. 2, 493-501

13 Jeannerod, M. (2001) Neural simulation of action: a unifying mechanism for motor cognition. Neuroimage 14, S103-S109

14 Decety, J. and Jeannerod, M. (1996) Fitts' law in mentally simulated movements. Behav. Brain Res. 72, 127-134

15 Jacob, P. and Jeannerod, M. (2003) Ways of Seeing, the Scope and Limits of Visual Cognition, Oxford University Press

16 Blakemore, S-J. et al. (2004) Social cognitive neuroscience: where are we heading? Trends Cogn. Sci. 8, 216-221

17 Baron-Cohen, S. (1995) Mindblindness: Essay on Autism and the Theory of Mind, Learning, Development and Conceptual Change, MIT Press

18 Leslie, A. and Thaiss, L. (1992) Domain specificity in conceptual development. Cognition 43, 225-251

19 Frith, U. and Frith, C.D. (2003) Development and neurophysiology of mentalizing. In The Neuroscience of Social Interaction (Frith, C. and Wolpert, D. eds), pp. 45-75, Oxford University Press

20 Saxe, R. et al. (2004) Understanding other minds: linking developmental psychology and functional neuroimaging. American Review of Psychology 55, 87-124

21 Gopnik, A. and Wellman, H.M. (1994) The theory theory. In Mapping the Mind: Domain Specificity in Cognition and Culture (Hirschfeld, L.A. and Gelman, S.A. eds), pp. 257-294, Cambridge University Press

22 Gordon R. (1995) Folk psychology as simulation. In Folk Psychology (Davies, M. and T. Stone, T. eds), pp. 60-73, Blackwell

23 Goldman, A. (1995) Interpretation psychologized. In Folk Psychology (Davies, M. and Stone, T. eds), pp. 74-99, Blackwell

24 Allison, T. et al. (2000) Social perception from visual cues: role of the STS region. Trends Cogn. Sci. 4, 267-278

25 Leslie, A. and Polizzi, P. (1998) Inhibitory processing in the false belief task: two conjectures. Dev. Sci. 1, 247-253

26 Woodward, A.L. (1998) Infants selectively encode the goal object of an actor's reach. Cognition 69, 1-34

27 Searle, J. (1983) Intentionality, an Essay in the Philosophy of Mind, Cambridge University Press

28 Pacherie, E. (2000) The content of intentions. Mind and Language 15, 400-432

29 Grice, H.P. (1989) Studies in the Way of Words, Harvard University Press

30 Sperber, D. and Wilson, D. (1986) Relevance, Communication and Cognition, Harvard University Press

31 Gergely, G. et al. (1995) Taking the intentional stance at 12 months of age. Cognition 56, 165-193

32 Csibra, G. et al. (1999) Goal attribution without agency cues: the perception of 'pure reason' in infancy. Cognition 72, 237-267

33 Heider, F. and Simmel, M. (1944) An experimental study of apparent behavior. Am. J. Psychol. 57, 243-259

34 Castelli, F. et al. (2000) Movement and mind: a functional imaging study of perception and interpretation of complex intentional movement patterns. Neuroimage 12, 314-325

35 Berry, D.S. and Springer, K. (1993) Structure, motion, and preschoolers' perception of social causality. Ecological Psychology 5, 273-283

36 Kuhlmeier, V. et al. (2003) Attribution of dispositional states by 12-month olds. Psychol. Sci. 14, 402-408

37 Spelke, E. et al. (1995) Infants' knowledge of object motion and human action. In Causal Cognition, a Multidisciplinary Debate (Sperber, D. et al., eds), pp. 44-78, Oxford University Press

38 Adolphs, R. (1999) Social cognition and the human brain. Trends Cogn. Sci. 3, 469-479

39 Adolphs, R. et al. (1998) The human amygdala in social judgment. Nature 393, 470-474

40 Perrett, D.I. et al. (1982) Visual neurones responsive to faces in the monkey temporal cortex. Exp. Brain Res. 47, 329-342

41 Perrett, D.I. et al. (1989) Frameworks of analysis for the neural representation of animate objects and actions. J. Exp. Biol. 146, 87-113 
42 Keysers, C. and Perrett, D.I. The neural correlates of social perception: a Hebbian network perspective. Trends Cogn. Sci. (in press)

43 Hietanen, D.K. and Perrett, D.I. (1993) Motion sensitive cells in the macaque superior temporal polysensory area. 1 Lack of response to the sight of the animal's own limb movement. Exp. Brain Res. 93, 117-128

44 Hietanen, D.K. and Perrett, D.I. (1996) Motion sensitive cells in the macaque superior temporal polysensory area: response discrimination between self-generated and externally generated pattern motion. Behav. Brain Res. 76, 155-167

45 Currie, G. (1995) Visual imagery as the simulation of vision. Mind and Language 10, 25-44
46 Tomasello, M. and Call, J. (1997) Primate Cognition, Oxford University Press

47 Kumashio, M. et al. (2003) Natural imitation induced by joint attention in Japanese monkeys. Int. J. Psychophysiol. 50, 81-99

48 Meltzoff, A.N. and Moore, M.K. (1997) Explaining facial imitation. A theoretical model. Early Development and Parenting 6, 179-192

49 Meltzoff, A.N. (1995) Understanding intentions of others: reenactment of intended acts by 18 months-old children. Dev. Psychol. 31, 838-850

50 Meltzoff, A.N. and Decety, J. (2003) What imitation tells us about social cognition: a rapprochement between developmental psychology and cognitive science. In The Neuroscience of Social Interaction (Frith, C. and Wolpert, D. eds), pp. 109-130, Oxford University Press

\section{Have you contributed to an Elsevier publication?}

\section{Did you know that you are entitled to a $\mathbf{3 0} \%$ discount on books?}

A $30 \%$ discount is available to ALL Elsevier book and journal contributors when ordering books or stand-alone CD-ROMs directly from us.

To take advantage of your discount:

1. Choose your book(s) from www.elsevier.com or www.books.elsevier.com

2. Place your order

Americas:

TEL: +18007824927 for US customers

TEL: +18004603110 for Canada, South \& Central America customers

FAX: +1 3144534898

E-MAIL: author.contributor@elsevier.com

All other countries:

TEL: +44 1865474010

FAX: +441865 474011

E-MAIL: directorders@elsevier.com

You'll need to provide the name of the Elsevier book or journal to which you have contributed. Shipping is FREE on pre-paid orders within the US, Canada, and the UK.

If you are faxing your order, please enclose a copy of this page.

3. Make your payment

This discount is only available on prepaid orders. Please note that this offer does not apply to multi-volume reference works or Elsevier Health Sciences products. 